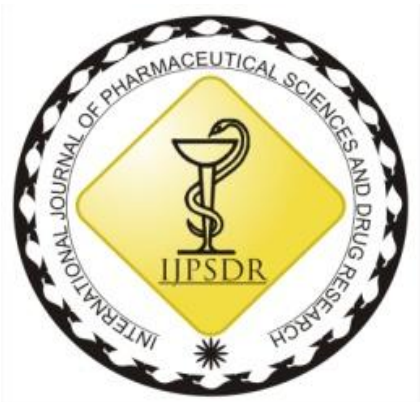

\author{
RESEARCH ARTICLE
}

ISSN: 0975-248X CODEN (USA): IJPSPP

$(\mathrm{cc})$ EY-NC-SA

\title{
Study on Bioactive Compounds of Jania rubens against Methicillin and Vancomycin Resistant Staphylococcus aureus
}

\author{
Sasikala Chenniyappan*, Geetharamani Durairaj, K Evetha \\ Department of Microbiology, Dr. N. G. P. Arts and Science College, Coimbatore- 641648, Tamil Nadu, India
}

Copyright (C) 2019 Sasikala Chenniyappan et al. This is an open access article distributed under the terms of the Creative Commons AttributionNonCommercial-ShareAlike 4.0 International License which allows others to remix, tweak, and build upon the work non-commercially, as long as the author is credited and the new creations are licensed under the identical terms.

\begin{abstract}
The study is planned to find the antimicrobial activity of the extract of Jania rubens and to isolate the bioactive compound against MRSA and VRSA. Jania rubens collected from Mandapam (Pudumadam) Coastal water, East coast of India and extracted with ethanol. Antibacterial activity of J. rubens was tested against gram positive, gram negative bacteria and drug resistant bacteria). The antibacterial activities were expressed as zone of inhibition, minimum inhibitory concentration (MIC) and minimum bactericidal concentration (MBC) Identification of compounds from crude extract of $J$. rubens carried by column chromatography, thin layer chromatography and NMR analysis. Finally $J$. rubens could serve as useful source of new antibacterial agent.
\end{abstract}

Keywords: J. rubens, seaweed, resistant, antimicrobial, bioactive, Staphylococcus aureus.

*Corresponding author: Mrs. Sasikala Chenniyappan

Address: Department of Microbiology, Dr. N. G. P. Arts and Science College, Coimbatore- 641648, Tamil Nadu, India

E-mail $\bowtie$ : sasikalac@drngpasc.ac.in

Relevant conflicts of interest/financial disclosures: The authors declare that the research was conducted in the absence of any commercial or

financial relationships that could be construed as a potential conflict of interest.

Received: 25 October, 2019; Revised: 13 November, 2019; Accepted: 20 November, 2019; Published: 30 November, 2019

\section{INTRODUCTION}

Seaweeds are macroscopic algae, which form an important component of the marine living source. They are largely available in shallow coastal waters wherever there is substratum on which they can grow and flourish. In India all kind of seaweeds are present in the coastal region namely green, red, brown and blue green. There are 800 different species of seaweeds in the Indian coast. Seaweeds are photosynthetic plants that inhabit the coastal region commonly within the rocky intertidal or submerged reef like habitats and have even been one of the richest and most promising sources of bioactive primary and secondary metabolites. The intertidal zone of marine environment is a competitive zone for light, nutrients as well as space and under such extreme conditions seaweeds have evolved physiologically to eventually develop chemical defense mechanisms against predators to enhance its survival for production of metabolites such as carotenoids, terpenoids, xanthophylls, chlorophylls, vitamins, saturated and poly unsaturated fatty acids, amino acids, acetogenins, antioxidants such as polyphenol and alkaloids, polysaccharides such as agar, carrageenan and alginate. Sea weeds are also used as cattle feed and manure. Seaweeds are good emulsifiers and possess good water holding, oil holding, gelling and binding properties, which makes it quite important in the food industry. Seaweeds form the richest renewable source of ample bioactive compounds that promote them as a vital candidate in 
therapeutics, especially for drug development. These compounds can be exploited to combat antimicrobial resistance in microorganisms. [1] The red seaweeds are used as food also for several medical applications. Brown algae are known to have a high capacity for heavy metal removal. They possess antimicrobial [2], antioxidant [3], immune stimulant, antiviral and anti cancer properties. Decreased efficiency and resistant of pathogen to antibiotics has demanded the development of new alternatives. The antibacterial activities of seaweeds were analyzed against human pathogenic bacteria. The secondary metabolites were extracted using various solvents like methanol [4], ethanol and acetone. [5-6] This compound could be exploited as potential lead molecule against broad spectrum drug development. The previous findings of seaweed metabolites showed effective inhibition of multi drug resistant pathogens. [7] The results also affirm the potential of seaweeds as an important natural source of antimicrobial compounds for pharmaceutical industries. [8] The present study is focused to explore antimicrobial property of the selected seaweed J. rubens against predominant pathogenic and drug resistant bacteria. Further the study to be extended to isolate the functional compound had shown the antimicrobial property using purification techniques.

\section{MATERIALS AND METHODS}

\section{Collection of seaweed}

Live and healthy sample of marine seaweed J. rubens was collected by hand picking at Mandapam (Pudumadam) coastal water, East coast of India, Lat 9०16'N; Long 780 69' E. . The collected samples were cleaned with seawater to remove all the extraneous matter such as epiphytes, sand, particles, pebbles and shells and then brought to the laboratory in plastic bags. The samples were then thoroughly washed with freshwater, blotted and spread out at room temperature for drying. Shade dried samples were grounded to fine powder. The powered samples were then kept in sterile bags, sealed properly and stored at room temperature for further use.

\section{Herbarium preparation}

For the morphological identification of the collected seaweed, the whole part of the fresh seaweed was placed between the multiple layers of filter paper and bundled tightly until complete dryness is obtained. This prevents fungal contamination. The filter paper was changed with the interval of every three days. The seaweed was then removed and pasted on herbarium sheet $(24 \mathrm{~cm} \times 43 \mathrm{~cm})$ using gum.

Identification of seaweed

The seaweed was identified and authenticated at Marine Algal Research Station, Central salt and Marine Research Institute [Council of Scientific and Industrial Research], Mandapam Camp - 623519, Ramanathapuram district, Tamil Nadu, India. Extraction of seaweed [9]
Sequential extraction of seaweed powder was performed using ethanol. The dried J. rubens (50gms) was mixed thoroughly with $112 \mathrm{ml}$ of the solvent in separate flask and was kept in magnetic stirrer at 1400 rpm for 1 week. The mixture was filtered separately and concentrated using Rotary vacuum evaporator. The concentrated crude extract was refrigerated until tested. Microbial strains

Bacterial strains used for the antibacterial study were as follows: Enterococcus faecalis, Streptococcus pyogenes, Escherichia coli, Klebsiella sp., Salmonella typhi, Pseudomonas aeruginosa, Methicillin resistant S. aureus and Vancomycin resistant $S$. aureus. Microbial strains were obtained from Bioline Laboratories, Coimbatore and Kovai Medical center and Hospital, Coimbatore. The bacterial stock cultures were maintained on Nutrient Agar medium at $4{ }^{\circ} \mathrm{C}$

Antibacterial assay

Preparation of inoculums

Bacterial inoculums were grown in nutrient broth for overnight. The cell density was compared with 0.5 McFarland turbidity standards (approximately $1.5 \times 10^{8}$ $\mathrm{CFU} / \mathrm{ml}$ ).

Screening of antibacterial activity using disc diffusion

The antibacterial activity of $J$. rubens extracted with different solvent were tested against human pathogenic organisms (E. faecalis, S. pyogenes and S. aureus, E. coli, $P$. aeruginosa, Klebsiella sp., and $S$. typhi) were measured using the disc diffusion method. Muller Hinton Agar plates were prepared. Test organisms were swabbed on the Muller Hinton Agar plates. The sterile discs incorporated with each extracts were placed and incubated at $37^{\circ} \mathrm{C}$ for 24 hours. The zone of inhibition was measured with ruler after 24 hours of incubation.

Minimal inhibitory concentration

To determine the minimum inhibitory concentration (MIC) of the crude extracts of J. rubens tube dilution technique was employed. [10] This test was done to determine the lowest concentration of crude extracts that inhibit the growth of bacteria. A loop full of exponential phase bacterial culture corresponding to 0.5 Macfarlands opacity was inoculated into nutrient broth with different concentration of extracts ranging from 4000, 2000, 1000, 500, 125, 62.5, 31.25 and $15.625 \mu \mathrm{g} / \mathrm{ml}$. The tubes were then incubated at $37^{\circ} \mathrm{C}$ for 24 hours. Turbidity was observed after the incubation period. MIC was defined as the lowest concentration of crude extract that completely inhibited the visible growth of the test microorganisms.

\section{Minimum Bactericidal concentration}

The Minimum Bactericidal concentration (MBC) is the minimum concentration of an active compound which kills the given bacterium. MBC of J. rubens crude extract was determined by plating loop full of bacterial solution from each MIC assay well with growth inhibition into freshly prepared MHA. The plates were incubated at $37^{\circ} \mathrm{C}$ for 24 hours. The $\mathrm{MBC}$ was recorded as the lowest concentration of the extract that did not 
permit any visible bacterial growth after the period of incubation

Separation and purification of bioactive compounds column chromatography

The first step in the isolation of natural compounds from the crude extract usually consists of sequential gradient partition with solvents. Column chromatography was carried out using the crude extract of $J$. rubens that produced significantly higher antibacterial activity over the other solvent extract towards majority of human pathogenic organisms. The crude ethanolic extract of $J$. rubens was absorbed on to silica gel (60-120 mesh size) in a glass column and chromatographed. The column was eluted with gradients of solvents such as hexane < hexane: ethyl acetate < ethyl acetate < ethyl acetate: acetone < acetone $<$ acetone: ethanol < ethanol. The column was continuously eluted with solvents of various ratios. The solvents used for elution was hexane (100\%), hexane: ethyl acetate (90:10), hexane: ethyl acetate (60:40), ethyl acetate $(100 \%)$, ethyl acetate: acetone (90:10), ethyl acetate: acetone (60:40), acetone $(100 \%)$, acetone: ethanol (90:10), acetone: ethanol (60:40) and ethanol $(100 \%)$. The column was finally washed with ethanol. Each fraction of $10 \mathrm{ml} / 45$ minutes was collected. 19 different fractions of extract were collected. These fractions were stored under refrigeration for further analysis.

\section{Thin layer chromatography}

All the fractions collected from column chromatography were subjected to analytical TLC. Analytical TLC was carried out using silica gel with 0.2 $\mathrm{mm}$ thickness on sterile glass slides. The plate was marked with soft pencil. The glass capillaries were used to load the fractions on the TLC plates. The sample was loaded at a distance of $1 \mathrm{~cm}$ and was developed in the chromatographic chamber with mobile phase. Mobile phase comprised of increasing polarity of various solvent mixtures as performed for column chromatography. The solvents such as hexane (100\%), hexane: ethyl acetate (90:10), hexane: ethyl acetate $(60: 40)$, ethyl acetate $(100 \%)$, ethyl acetate: acetone (90:10), ethyl acetate: acetone (60:40), acetone (100\%), acetone: ethanol (90:10), acetone: ethanol (60:40) and ethanol $(100 \%)$ were used to separate various fractions on the TLC plate. The developed plates were dried under normal air and the spots were visualized under UV dark chamber of $365 \mathrm{~nm}$. These fractions were then subjected to antibacterial study using disc diffusion assay.

\section{Antibacterial assay for drug resistant strains}

The effective fractions of $J$. rubens eluted in column chromatography were tested against Methicillin resistant $S$. aureus and Vancomycin resistant $S$ aureus and using disc diffusion method.

Nuclear magnetic resonance analysis

${ }^{13} \mathrm{C}$ nuclear magnetic resonance analysis

${ }^{13} \mathrm{C}$ NMR spectra of fraction 19 of J. rubens was recorded using a BURKER spectrometer in $\mathrm{CdCl}_{3}$ as solvent and they were assigned by comparison of chemical shifts and coupling constants with those of related compounds.

${ }^{1} \mathrm{H}$ nuclear magnetic resonance analysis

${ }^{1} \mathrm{H}$ NMR spectra of fraction 19 of J. rubens was recorded at $23^{\circ} \mathrm{C}$ in $\mathrm{CdCl}_{3}$ using a BURKER spectrometer and they were assigned by comparison of chemical shifts and coupling constants with those of related compounds.

\section{RESULTS AND DISCUSSION}

\section{Collection and identification of seaweed}

The seaweed was collected from Mandapam coastal area, East coast of India and the Geographical location was given below Table 1 and Figure 1.

\begin{tabular}{lccc}
\multicolumn{4}{l}{ Table 1: Collection of Seaweed } \\
$\begin{array}{ccc}\text { S. } \\
\text { No }\end{array}$ & $\begin{array}{c}\text { Name of the } \\
\text { Seaweed }\end{array}$ & GPS Location & Geographical location \\
\hline 1. & J. rubens & Pudumadam & NO9० $16.37 ;$ EO79॰00.69
\end{tabular}

Fig. 1: J. rubens
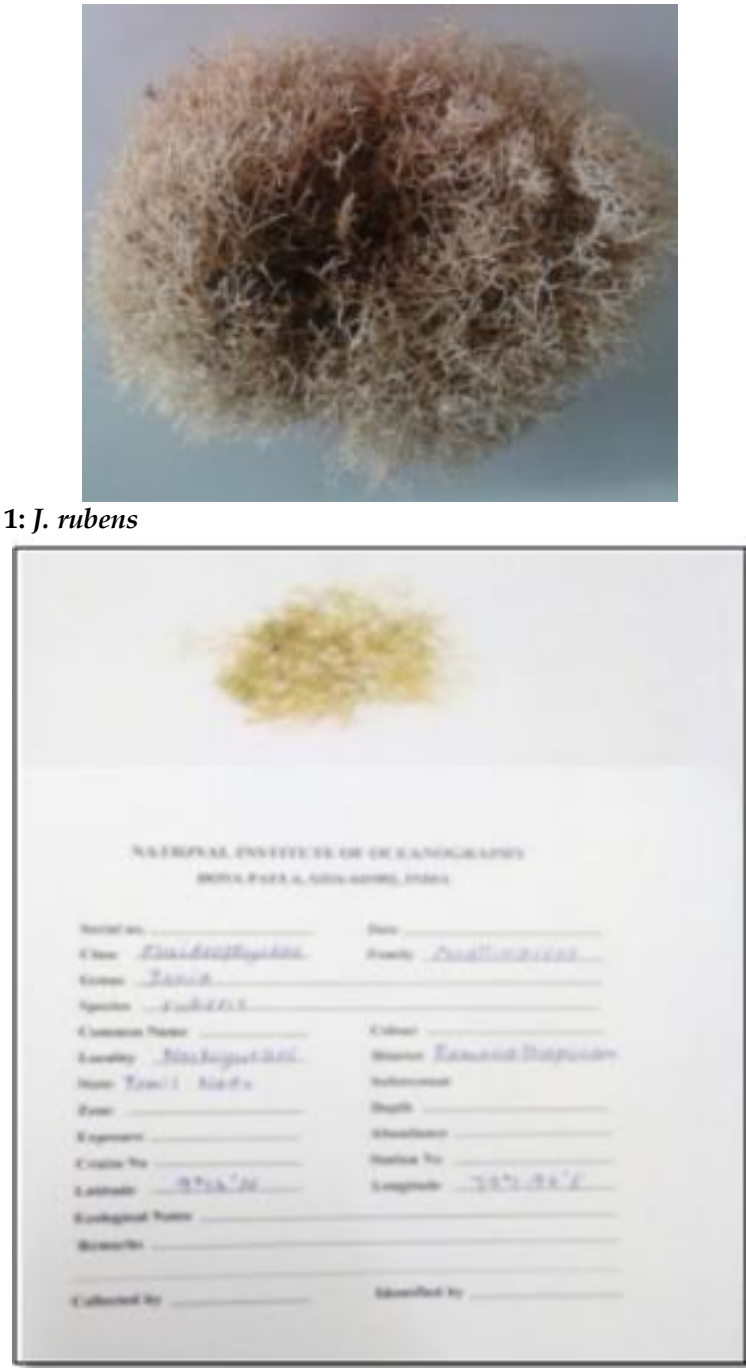

Fig. 2: Herbarium preparation of J. rubens.

\section{Herbarium preparation}

The whole part of the seaweed was preserved in the form of Herbarium for the morphological identification (Figure 2). 


\section{Identification of seaweed}

The seaweed was identified and authenticated by Dr. V. Veeragurunathan, Scientist, Marine Algal Research Station, Central Salt and Marine Research Institute, Mandapam camp, Ramanathapuram, Tamilnadu, India. The classification system of the seaweed taken for the study was mentioned in Table 2.

Table 2: Identification of Seaweed

\begin{tabular}{ccccccc}
\hline $\begin{array}{c}\text { S. } \\
\mathbf{N} \\
\mathbf{0}\end{array}$ & $\begin{array}{c}\text { Name of } \\
\text { species }\end{array}$ & Type & Class & Sub class & Order & Family \\
\hline 1. & J. rubens & $\begin{array}{c}\text { Red } \\
\text { Algae }\end{array}$ & $\begin{array}{c}\text { Florideoph } \\
\text { yceae }\end{array}$ & $\begin{array}{c}\text { Corallinoph } \\
\text { ycidae }\end{array}$ & $\begin{array}{c}\text { Corallii } \\
\text { nales }\end{array}$ & $\begin{array}{c}\text { Corallina } \\
\text { ceae }\end{array}$ \\
\hline
\end{tabular}

\section{Extraction of seaweeds}

The crude extract was collected from J. rubens using various solvents such as hexane, butanol, acetone and ethanol. The extract was then concentrated under rotary vacuum evaporator and soxhlet apparatus. The dried material to be preserved under $4^{\circ} \mathrm{C}$ until further use.

Antibacterial assay

The antibacterial assay for different solvent extract was measured using disc diffusion method. Among the extracts tested, the ethanolic extract showed maximum activity against various bacteria. The zone of inhibition was measured and tabulated (Table 3). The present study stated that the ethanolic extract of J. rubens showed effective inhibition against $E$. faecalis and $S$. pyogenes (Figure 4).

\section{Minimum inhibitory concentration}

The minimum inhibitory concentration is the lowest concentration of extract to kill or inhibit the growth of microorganisms. The MIC was performed for E. faecalis and the broth was checked for OD at $540 \mathrm{~nm}$ and the results were tabulated (Table 4). The Minimum Inhibitory Concentration for E. faecalis was found to be $1000 \mu \mathrm{g} / \mathrm{ml}$ (Figure 5).
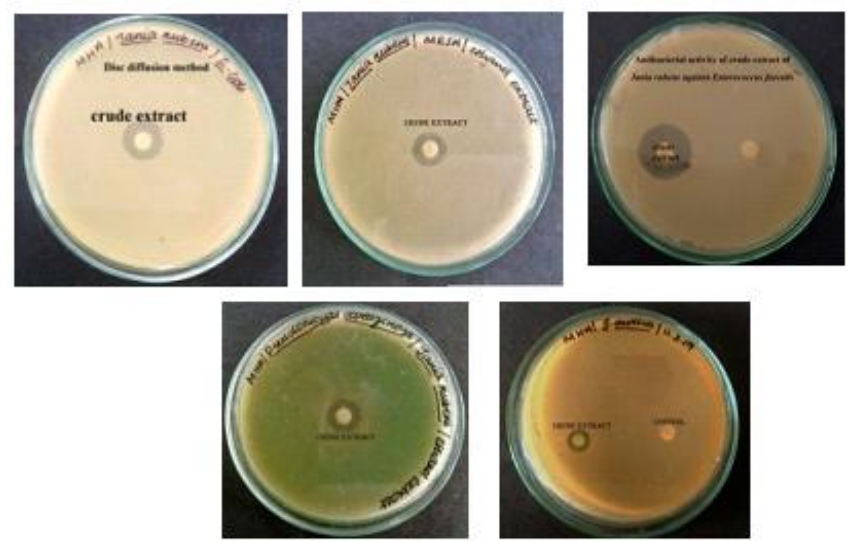

Fig. 4: Antibacterial activity of crude extract of $J$. rubens using Disc diffusion method

\section{Minimal Bactericidal Concentration}

MBC measures the lowest concentration of bioactive compounds that kills the bacterial isolate. In the present study the growth was completely arrested in the tube containing $4000 \mu \mathrm{g} / \mathrm{ml}$ of the crude extract. Thus, the crude extract of $J$. rubens has complete bactericidal activity at $4000 \mu \mathrm{g} / \mathrm{ml}$ (Figure 6).

Separation and purification of bioactive compounds: Column chromatography

Column chromatography was performed for the ethanolic extract of $J$. rubens and 19 different fractions were collected using 10 different solvents.

Table 3: Antibacterial activity of ethanolic extract of $J$. rubens against the selected pathogens.

\begin{tabular}{cc}
\hline Bacterial strains & \begin{tabular}{c} 
Antibacterial activity of J. rubens \\
\cline { 2 - 2 }
\end{tabular} \\
$\begin{array}{c}\text { Diameter of zone of inhibition } \\
(\mathbf{m m})^{*}\end{array}$ \\
\hline E. coli & $09.00 \pm 0.81$ \\
E. faecalis & $26.00 \pm 0.56$ \\
S. aureus & $11.00 \pm 0.54$ \\
P. aeruginosa & $11.00 \pm 0.41$ \\
S. pyogenes & $22.00 \pm 0.75$ \\
K. pneumonia & $11.00 \pm 0.41$ \\
S. typhi & $10.00 \pm 0.48$ \\
Methicillin resistant S. aureus & $10.00 \pm 0.45$ \\
Vancomycin resistant S. aureus & $11.00 \pm 0.35$ \\
\hline
\end{tabular}

\pm The value indicates the standard Error Mean of experiments done in triplicates.

Table 4: Analysis of Minimal Inhibitory concentration

\begin{tabular}{lccccccccc}
\hline \multirow{2}{*}{ Organism } & \multicolumn{7}{c}{ Different concentration of Seaweed Extract $(\mu \mathrm{g} / \mathrm{ml})$} \\
\cline { 2 - 11 } & $\mathbf{1 5 . 6 2 5}$ & $\mathbf{3 1 . 2 5}$ & $\mathbf{6 2 . 5}$ & $\mathbf{1 2 5}$ & $\mathbf{2 5 0}$ & $\mathbf{5 0 0}$ & $\mathbf{1 0 0 0}$ & $\mathbf{2 0 0 0}$ & $\mathbf{4 0 0 0}$ \\
\hline E. faecalis & 0.97 & 0.79 & 0.72 & 0.62 & 0.51 & 0.38 & 0.01 & 0.01 & 0.00
\end{tabular}
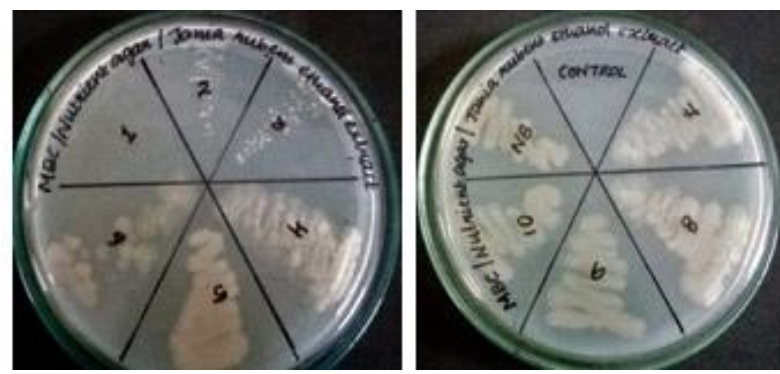

Fig. 6: Analysis of Minimal Bactericidal Concentration
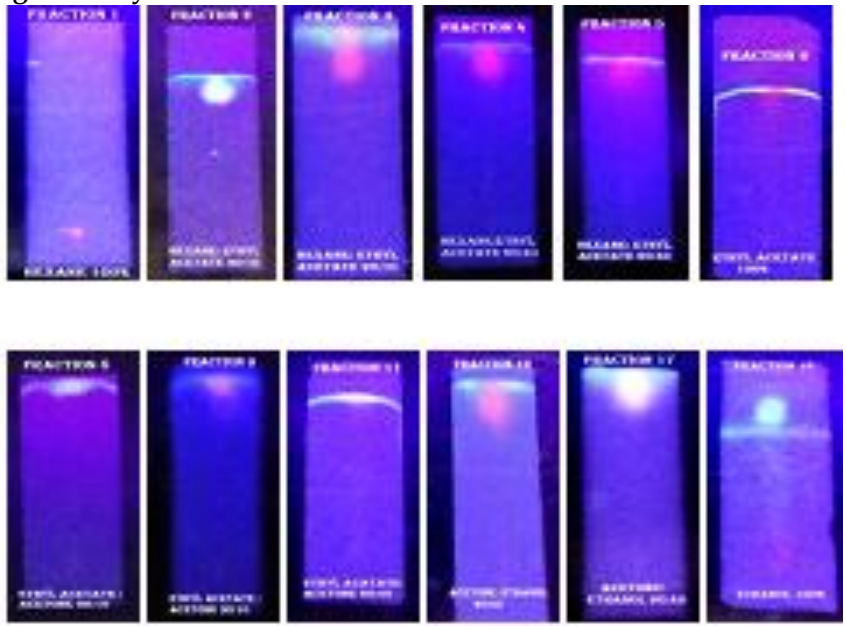

Fig. 7: Purification of active compounds using Thin Layer Chromatography

Thin layer chromatography

Analytical TLC was carried out for the fractions collected using column chromatography. The purity of fractions collected was tested using TLC and the $R_{f}$ value of each fraction was calculated and tabulated (Figure 7). 
Table 5: Antibacterial activity of eluted fractions from column chromatography and thin layer chromatography

\begin{tabular}{|c|c|c|c|c|c|}
\hline \multirow{2}{*}{$\begin{array}{l}\text { S. } \\
\text { No }\end{array}$} & \multicolumn{2}{|c|}{ Column Chromatography } & \multirow{2}{*}{$\begin{array}{c}\text { Thin layer chromatography } \\
\text { Rf value }\end{array}$} & \multicolumn{2}{|c|}{ Antibacterial activity of eluted fractions of J. rubens (zone of inhibition in $\mathrm{mm}$ ) } \\
\hline & Mobile phase (solvent used) & Fraction & & E.faecalis & S. pyogenes \\
\hline 1 & Hexane $-100 \%$ & 1 & 0.036 & - & - \\
\hline 2 & Hexane: Ethyl acetate- 90:10 & 2 & 0.712 & - & - \\
\hline 3 & Hexane: Ethyl acetate- 90:10 & 3 & 0.713 & - & - \\
\hline 4 & Hexane: Ethyl acetate- 60:40 & 4 & 0.742 & $8.23 \pm 0.15$ & - \\
\hline 5 & Hexane: Ethyl acetate- $60: 40$ & 5 & 0.744 & $8.06 \pm 0.2$ & - \\
\hline 6 & Ethyl acetate-100\% & 6 & 0.735 & $7.13 \pm 0.05$ & - \\
\hline 7 & Ethyl acetate- $100 \%$ & 7 & 0.738 & $7.1 \pm 0.17$ & $6.06 \pm 0.1$ \\
\hline 8 & Ethyl acetate: acetone- 90:10 & 8 & 0.44 & $7.13 \pm 0.05$ & - \\
\hline 9 & Ethyl acetate: acetone- 90:10 & 9 & 0.46 & $6.06 \pm 0.1$ & - \\
\hline 10 & Ethyl acetate: acetone- $60: 40$ & 10 & 0.742 & $8.23 \pm 0.15$ & $6.06 \pm 0.1$ \\
\hline 11 & Ethyl acetate: acetone- 60:40 & 11 & 0.744 & $7.1 \pm 0.17$ & $7.13 \pm 0.05$ \\
\hline 12 & Acetone- $100 \%$ & 12 & 0.754 & - & $7.1 \pm 0.17$ \\
\hline 13 & Acetone- $100 \%$ & 13 & 0.761 & $8.23 \pm 0.15$ & $7.13 \pm 0.05$ \\
\hline 14 & Acetone: Ethanol 90:10 & 14 & 0.947 & - & $8.23 \pm 0.15$ \\
\hline 15 & Acetone: Ethanol 90:10 & 15 & 0.946 & $7.1 \pm 0.17$ & - \\
\hline 16 & Acetone: Ethanol 60:40 & 16 & 0.931 & - & $10.26 \pm 0.11$ \\
\hline 17 & Acetone: Ethanol 60:40 & 17 & 0.930 & - & $11.16 \pm 0.06$ \\
\hline 18 & Ethanol - 100\% & 18 & 0.732 & $13.23 \pm 0.15$ & $11.16 \pm 0.06$ \\
\hline 19 & Ethanol - $100 \%$ & 19 & 0.823 & $11.16 \pm 0.06$ & $11.16 \pm 0.06$ \\
\hline
\end{tabular}

\pm The value indicates the standard Error Mean of experiments done in triplicates.

\section{Antibacterial assay for eluted fractions}

The antibacterial assay for the eluted fractions was measured using disc diffusion method. The zone of inhibition was measured and tabulated (Figure 8) (Table 5).
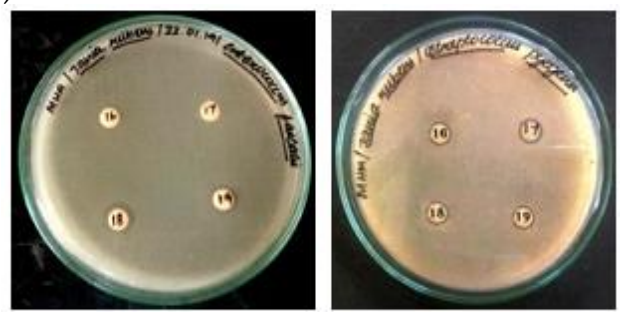

Fig. 8: Antibacterial assay of eluted fractions against E. faecalis and S. pyogenes
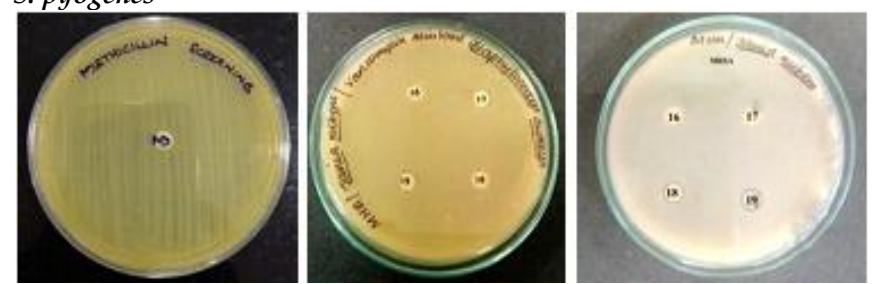

Fig. 9: Antibacterial assay of effective fractions against MRSA and VRSA.

From the above screened fractions, fraction 16, 17, 18 and 19 showed maximum activity against $E$. faecalis and S. pyogenes.

Antibacterial assay for drug resistant strains

The effective fractions were then subjected to antibacterial assay against MRSA and VRSA using the disc diffusion method. The zone of inhibition was measured and tabulated. Fraction 19 showed maximum activity against MRSA and VRSA and Fraction 16, 17, 18 showed moderate activity (Table 6 and Figure 9).

NMR spectral analysis of isolated compound ${ }^{13} \mathrm{C}$ NMR Spectrum

The ${ }^{13} \mathrm{C}$ NMR $(\delta \mathrm{ppm})$ spectrum shows the peak values at $\delta 77.40,76.98$ and 76.56 are due to a tertiary and quarternary carbons. The peak value at $\delta 31.94$ was attributed to cyclic $\mathrm{CH}$ group and the singlet 29.70 was attributed to cyclic $\mathrm{CH} 2$ group (Figure 10).

${ }^{1} \mathrm{H}$ NMR Spectrum

The ${ }^{1} \mathrm{H}$ NMR $(\delta$ ppm) spectrum shows the peak values at $\delta 0.890$ and 1.272 which were assigned to methyl groups. The peak at $\delta 4.738$ is due to quaternary hydrogen attached to the side chain.

Table 6: Antibacterial activity of fractions of J. rubens against drug resistant strains of $S$. aureus

\begin{tabular}{cccc}
\hline \multirow{2}{*}{ S. No. } & \multirow{2}{*}{ Fractions } & \multicolumn{2}{c}{ Diameter of zone of inhibition (mm) } \\
\cline { 3 - 4 } & & MRSA & VRSA \\
\hline 1 & 16 & $8.06 \pm 0.5$ & $8.13 \pm 0.11$ \\
2 & 17 & $8.23 \pm 0.15$ & $8.06 \pm 0.2$ \\
3 & 18 & $9.13 \pm 0.05$ & $9.16 \pm 0.11$ \\
4 & 19 & $10 \pm 0.27$ & $12.16 \pm 0.05$ \\
\hline
\end{tabular}

\pm The value indicates the standard Error Mean of experiments done in triplicates

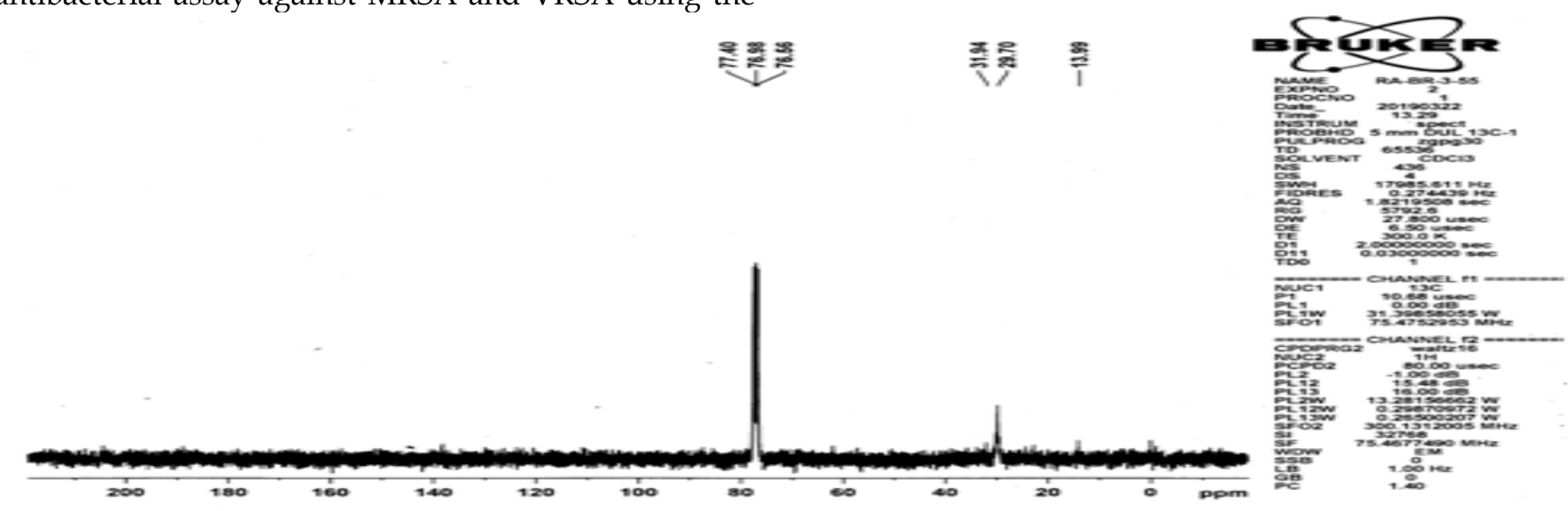

Fig. 10: ${ }^{13} \mathrm{C}$ NMR of isolated compound 


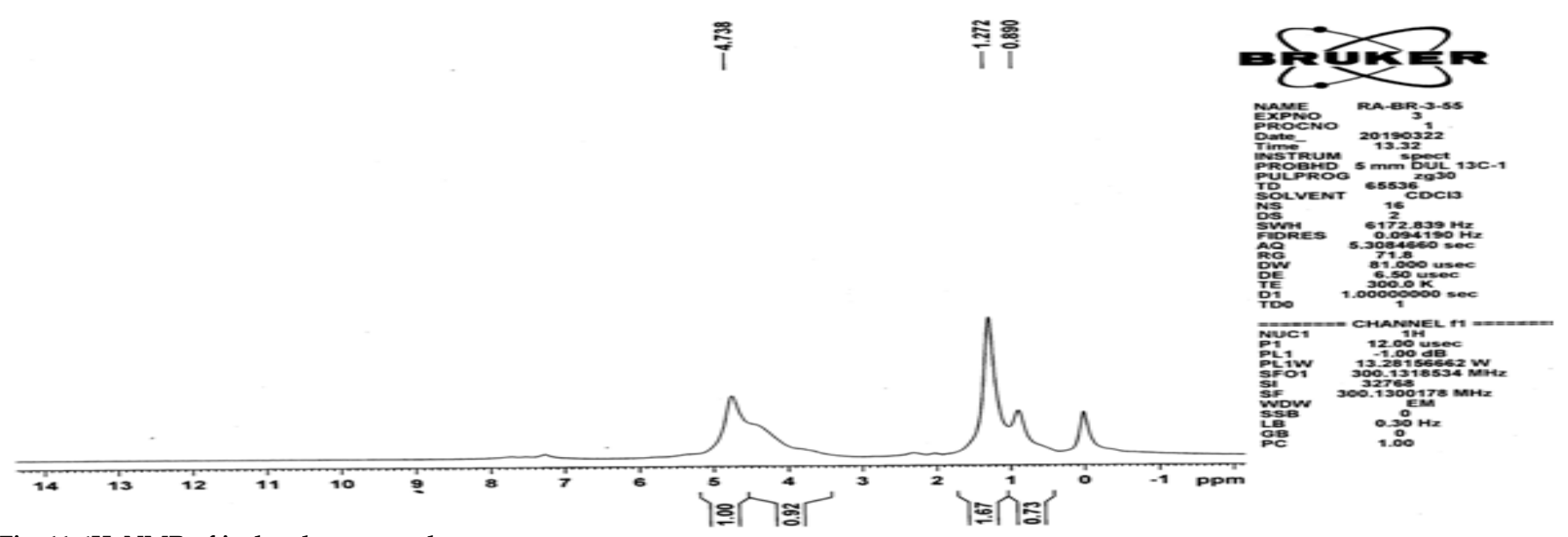

Fig. 11: ${ }^{1} \mathrm{H}$ NMR of isolated compound

\section{DISCUSSION}

Seaweeds are potential renewable resources in the marine environment. Kim and Lee [11] proved the ethanolic extract of seaweeds showed better antibacterial activity. The previous finding stated that the antibacterial compounds are more active against gram positive bacteria than gram negative bacteria. The resistance of gram negative bacteria towards antibacterial substance is related to the hydrophilic surface of their outer membrane which is rich in lipopolysaccharide molecules, presenting a barrier to the penetration of numerous antibiotic molecules. The membrane is also associated with the enzyme in the periplasmic space which are capable of breaking down the molecules introduced from outside. However the Gram positive does not possess such outer membrane and cell wall. [12-13] The study showed the antimicrobial activity of the methanol, ethanol, chloroform and acetone extracts of the red alga J. rubens by disc diffusion method. ${ }^{[14]}$ The extracts upon phytochemical screening showed the presence of alkaloids, triterpenoids, steroids, tannin, saponin, coumarins, terpenoids, quinine, phytosteroids, phlobatannins and flavonoids. Among the four solvents tested, methanol and ethanol extracts exhibited the better activity. The present study stated that ethanolic extract of J. rubens showed maximum activity against Gram positive bacteria (E. feacalis $(26 \pm 0.56)$ and S. pyogenes $(22 \pm 0.75)$ reported that the species of Rhodophyta showed the highest antibacterial activity. In the present study the ethanolic extract of $J$. rubens exhibiting higher antibacterial activity was subjected to sequential extraction using column chromatography. 19 different fractions were obtained using 10 different combinations of solvents. These fractions subjected to antibacterial activity against $E$. feacalis and $S$. pyogenes. The fraction 16, 17, 18 and 19 exhibited effective antimicrobial activity. These effective fractions showed activity against MRSA and VRSA.

The present study was conducted to isolate the bioactive compound of $J$. rubens against MRSA and MRSA. J. rubens was collected from Eastern coastal area of Rameshwaram. The collected seaweed was washed, shad dried and powdered. The extract of J. rubens was prepared with ethanol, acetone, hexane and butanol as a solvent in a rotary vaccum evaporator. The extract was tested for antibacterial activity against the pathogens such as E. faecalis, S. pyogenes, E. coli, Klebsiella sp., S. typhi, P. aeruginosa, MRSA and VRSA. Ethanolic extract of J. rubens showed maximum activity for E. faecalis and S. pyogenes. The minimal inhibitory concentration of the J. rubens extract was tested against E. faecalis. The minimal inhibitory concentration was found to be $1000 \mu \mathrm{g} / \mathrm{ml}$. Minimum Lethal Concentration of the J. rubens was found to be $4000 \mu \mathrm{g} / \mathrm{ml}$. Column chromatography was carried out for separation of bioactive compounds using the crude extract of $J$. rubens that produced significantly higher antimicrobial activity. 19 different fractions were separated using 10 different combinations of solvents. The bioactive compound separated by column chromatography was analyzed by TLC. These fractions were subjected for effective inhibition against $E$. faecalis and S. pyogenes. The fraction 16, 17, 18 \& 19 showed effective inhibition. The effective fractions were tested against MRSA and VRSA. The fraction 19 showed maximum activity against MRSA and VRSA.

\section{ACKNOWLEDGEMENT}

The authors are grateful to DST- FIST Scheme, DBTStar Scheme, Management and Principal of Dr. N. G. P. Arts and Science College (Autonomous) for their extended support of this work.

\section{REFERENCES}

1. Sasikala C, Geetharamani D. Comparative study on antimicrobial activity of seaweeds. Asian Journal of pharmaceutical and clinical research. 2017: 10(12); 384-386.

2. Venkatesh R, Shanthi S, Rajapandian K, Elamathi S, Thenmozhi S, Radha N. Preliminary study on antixanthomonas activity, phytochemical analysis, and characterization of antimicrobial compounds from Kappaphycus alvarezii. Asian Journal of pharmaceutical and clinical research. 2011; 4(3):46-51.

3. Rajauria G. Abu-Ghannam N. Isolation and partial characterization of bioactive fucoxanthin from Himanthalia elongata brown seaweed: a TLC-based approach. International journal of analytical chemistry. 2013; Article ID 802573,6 pages. 
Sasikala Chenniyappan et al. / Study on Bioactive Compounds of Jania rubens against Methicillin.

4. Senthilkumar P, Sudha S. Antioxidant and antibacterial properties of methanolic extract of green seaweed Chaetomorphalinum from Gulf of Mannar: southeast coast of India. Jundishapur J Microbiol 2012; 5(2): 411-415.

5. Rosaline XD, Sakthivelkumar S, Rajendran K. Screening of selected marine algae from the coastal Tamil Nadu, South India for antibacterial activity. Asian Pacific Journal of Tropical Biomedicine 2012; 2(1): 140-146.

6. Mohy SM, Ahwany AMD. Bioactivity and phytochemical constituents of marine red seaweeds (Janiarubens, Corallinamediterranea and Pterocladiacapillacea). Journal of Taiban University for Science2016; 10:471-484.

7. Shanmughapriya S, Manilal A, Sujith S, Selvin J, Kiran GS, Natarajaseenivasan K. Antimicrobial activity of seaweeds extracts against multiresistant pathogens. Annals of Microbiology. 2008 Sep 1; 58(3):535-41.

8. Kavita K, Singh VK, Jha B. 24-Branched $\Delta 5$ sterols from Laurencia papillosa red seaweed with antibacterial activity against human pathogenic bacteria. Microbiological research. 2014 Apr 1; 169(4):301-6.
9. Naz S, Ahmad S, Rasool SA, Sayeed SA, Siddiqi R. Antibacterial activity directed isolation of compounds from Onosma hispidum. Microbiological research. 2006 Jan 1; 161(1):43-8.

10. Hong LS, Ibrahim D, Kassim J, Sulaiman S. Gallic acid: an anticandidal compound in hydrolysable tannin extracted from the barks of Rhizophora apiculata Blume. Journal of Applied Pharmaceutical Science. 2011 Aug 1;1(6):75.

11. Kim IH, Lee JH. Antimicrobial activities against methicillinresistant Staphylococcus aureus from macroalgae. Journal of Industrial and Engineering Chemistry. 2008; 14(5):568-72.

12. Shan B, Cai YZ, Brooks JD, Corke H. The in vitro antibacterial activity of dietary spice and medicinal herb extracts. International Journal of food microbiology. 2007 Jun 10; 117(1):112-9.

13. Kalemba DA, Kunicka A. Antibacterial and antifungal properties of essential oils. Current medicinal chemistry. 2003 May 1; 10(10):813-29.

14. Reddy GT, Unissa R, Mounika G. Antimicrobial activity of $J$. rubens against an Entero pathogen. Mintage Journal of Pharmaceutical and Medical Sciences, 2018: 6-8.

HOW TO CITE THIS ARTICLE: Chenniyappan S, Durairaj G, Evetha K. Study on Bioactive Compounds of Jania rubens against Methicillin and Vancomycin Resistant Staphylococcus aureus. Int. J. Pharm. Sci. Drug Res. 2019; 11(6): 409-415. DOI: 10.25004/IJPSDR.2019.110621 